\title{
Detailed Analysis of Teaching Reform of Design Basis Course
}

\author{
Dejun Wei \\ Department of Design \\ Shandong College of Arts \\ Jinan, China \\ e-mail:weidejun669@sina.com
}

\begin{abstract}
With the rapid development of Chinese economy and society, the design education sector is welcoming a rosy prospect while meeting an unprecedented challenge. So it is an important issue to how to cultivate creativity and international vision with outstanding design talent through Chinese design education. The idea of reforming design education is depended on changing of basic education. Author has been occupied in design basis education for many years, and author thinks "basis is root, and major is basis" that only the "root" changed can cause "basis" luxuriant. The paper emphasizes several key points, like the cultivation of aesthetic judgment and change of teaching thought and link to expound the point of reformation of basic teaching, through the teaching processes of sketch and color.
\end{abstract}

Keywords-Design basis; Aesthetic judgment; Reformation

\section{INTRODUCTION}

Design basis teaching is the fundamental of professional teaching. And the success of basis teaching will direct influence the future development of professional teaching. With increasing of level of design professional teaching, basic teaching ideas are changing stealthily. Currently proposing the ideas of "Big basis" are not only containing observational ability, aesthetic judgment, ability of mould of training students and design basis of plastic arts with expressive ability as principal thing, but also training of individuation of students, quality and standards. The broad of basis extension reveals that there are higher requirements for professional comprehensive qualities of major of art design students.

\section{Strengthen the Cultivation of Aesthetic Ability}

Sketch train as design basis is aim to cultivate observation method and ability; work by self, imitation and cognitive ability for space of students; create happen of imaging, development and logic ability, aesthetic and design ability. Through effective sketch train, students could free express design ideas by painterly language. It is not only a important link of training and cultivating design aesthetic judgment ability, but also a obbligato process of promoting design to art and a learning phase.
Sketch training of major of art design contain many factors, and the most important is cultivating good art feeling (or "aesthetic judgment"). It can give expression to a good idea only by improving aesthetic judgment, originality is kernel of art design, and the kernel is built by creating thought. During sketch training, the change of subjective ideas to sketch form with promethean is the result of creating thought, and we should develop creating thought ability throughout.

\section{Change OF TEACHING LINK AND IDEAS}

From view of design basis, sketch train is best doing under the task guidance, because it can express local sketch with creative design to a new entire shape of sketch. Author makes the entire sketch teaching process finished by two links, the first one is "students follow by teachers", the second one is "teachers follow by students", and it is aim at transforming students' ideas and cultivating arts feeling of students.

Earlier stage of the task is students going follow teachers' ideas, it is aim to break old habits and obtain new finds. The questions which should be found and solved are in looking side, and teaching way has experimental character. It hopes breaking the limits between habits and old rules, seeing familiar objects and scenes again.

Primeval training always brings some forcing, it will make most of students not be in a position to do it, and even some contradict emotion, uncertainty about teachers' "teaching". And they also not confidence about their works and feel every study before in vain.

Aim at this situation, teachers work is trying to make students changed their concepts and emphasize a series problems tirelessly, such as picture structure, superficial distribution, combination of dots, lines and faces and so on. And controlling students' pictures at any moment during the inspire process, finding out the "good feeling" of pictures and giving encourage.

"Stop" in necessity and focus on explaining, experience gained on key points to make every students get it in shortest time, and release their individuality gradually. About the work form, it should take short period as the principal thing, and tools most using charcoal pencil, charcoal bar and 
carbon bar, its purpose on emphasize the quick catch in feeling.

With accumulating of numbers of works, abilities of initiative selection and comprehensive process of students are strengthen step by step; sharp esthesis for real objects, aesthetic judgment and technique of expression of choosing and composition of a picture are improving gradually, and they are also relax in psychology little by little. There are constantly appear "light" points in pictures, and the sounds of inmost begin to emerging in pictures.

Just as a student wrote in his study notes:'During this week's work practice, I am not imitate the picture effect of powerful and vigorous and strong visual impact deliberately any more. On the contrary, I continue and improve my picture effect gradually, and try to using an start and soft way to express, using Cunca effect in Chinese painting on occasion, i.e. using the brush-side technique of carbon bar sweep once, feeling after attrition paper, and then a dim moonlight and vivid effect appear in paper...". Another student said:"We are practicing combine of dots, lines, and faces. I use the easiest and the most direct method to pave the picture, and it has just cost me 10 minutes. The content of picture is very simple, one white jar, one black jar, background is gray, and a light black thing that is called 'line' through behind. All the picture is simple and clear, black and white gradations are distinct, make people find it fresh and new ..."

The latter part of the teaching process is teachers following students, the teacher role from "drawing" to "pushing", making a relaxing atmosphere to let students release their characters abundantly, encouraging and pushing students thinking in a relaxing state, and enlightens students to apply reverse thinking, such as "call white black" or "by hook or by crook" and so on. The occasionality and experimental of method in practice will make a surprise visual effect, thus lead to find many kinds of possibilities again, so this should be given special attention. The final purpose of the teaching is to make every student all have guides and "unusual" expressions. Sometimes the feeling and ideas of "unusual" is so important that make techniques less importance.

To enrich students feeling, we should let students get rid of their usually expectation of sketch effective, and let them direct see the object first, and then analyze themselves feeling and features of objects through expressing. You can totally give up uninteresting aspects while incorporating, just standing out interested things and keeping initiative sober realize and dedicated attitude, using a refresh naïve view to treat objects. And motivating yourself expression desire from it, establishing the manifestation mode, and express your mental feelings during an enjoyable experience state.

In expressing forms, light and shade, lines and changes of objects, all the different changes of composition of a picture and technique of expression will generate "feeling", all kinds of changes will generate lively language by dealing with organization. So adding these train projects in specific sketch training could make students feel visual effect of different composition of a picture and different materials.

\section{Continuity of Teaching of Sketch And Color}

As color teaching of design major, it is cultivating the apply ability of subjective color consciousness and control color of students, emphasizing objects' color analysis and reconstitution, especially application and expression of subjective consciousness of color, while be capable of inspiring and developing logical thinking, associative thinking and creative thinking.

In color teaching, author not only teaches students correlation theories of color, but also and more emphasizes manifestation of various aspects of color, such as the feeling, consciousness, association, and image; through changing angle of view, composition of a picture, and location to make pictures generated different structure changes; inspires and encourage students to new thinking and new feeling; breaks the inherent models of students; reasoningly control students' pictures; and applies management of dots, lines, and faces, combination of color area, and permeation of design ideas to pursue complanation of color.

In practical color training, students are required not only to observe and express objective objects, but also to pay attention to rational analysis of objective images, and emphasize subjective consciousness and give play to individuality. On account of the earlier stage of sketch teaching, understanding concepts of students have been improved, organization structure consciousness of pictures have been enhanced, and organizational forms of color teaching have been generated relation with sketch teaching form naturally. Color teaching process is also divided into two parts: the form of work is mainly short period; teaching methods is similar with sketch teaching; and demands of tasks and works are important part in coming true teaching goal.

In order to cultivate creative thinking ability and various conception, ideas and methods of originality of students, and decompose and combine train of color and shape on purpose. That is to decompose nature shape at first, and form abstract symbol form, and then become constituent elements of the picture, the next is practicing as separate analyze tones, resolving and recombining according itself features, adding color factors of imagine, and intensifying subjective color motif.

In order to decrease the students' reliance of the original color of object and improve their color design ideas and cultivate their creative thinking of color, it has conducted the tonal training: under the condition of changing the relation between color factor of objects and colored light to apply tonal in different colors.

Into later period of phase of training of color, students should note naturally blending in design ideas, emphasizing decoration colors and design mixed, and using color rules and design principle to integrate nature color, from color mode to concretization, image, abstract, or signifying of pattern of manifestation of color to realize the inherent law of color. And connect with application of color in design. This connection is polyphyletic, widely, multi-layered, not 
point to any detailed design major, but suitable for all of design majors.

Since the concept of sketch teaching has some good for students' understanding, there is not any reverse problems existed in color teaching process.

\section{EXPERIENCE AND SHARE WITH STUdying Notes}

There is a weekly learning experience which is using to improve understand of design basis of students, and enhance the deeply understand of teachers to students. Students will put forward questions which not mention in class and summarize themselves studying processes. There are joy, depressed, being suddenly enlightened, puzzled, praises for teachers and queries of teachers. At the same time, teachers also find out questions, solve questions, and get gains. In organizing teaching process, there will be putting some excellent works on wall to encourage studying enthusiasm of students and clarify teaching ideas. This behavior is not only encourages students themselves, but also is good for whole students, making them studied together but developed respectively, adjusting ideas of students, and stimulating study atmosphere. There is also interspersed with communication between whole students and teachers by face by face, they question and answer each other, talk about themselves, eliminate the estrangements between them, and enhance relation between them.

Learning process: incomprehension - hesitation acceptance - appear different features - pleased smiles of students! The design elementary course education is hard but happy!

\section{REFERENCES}

[1] X. Wang,and M. Zhen (South Korea), Two-dimension Design Basis, Shanghai People's Fine Arts Publishing House, 2011

[2] Z. Zhou, Design Sketch.China, Higher Education Press, 2006 